\title{
Relationship between Pressure and both the Lattice Constant and Total Energy for $\mathrm{H}_{3} \mathrm{~S}$
}

\author{
Fatimah Alqahtani \\ School of Arts and Science \\ Clark Atlanta University, Atlanta, GA, 30314, USA
}

\begin{abstract}
Recently, researchers have discovered a superconductor of $\mathrm{H}_{3} \mathrm{~S}$ with the critical temperature $T_{c}$ above $200 \mathrm{~K}$ by compressing $\mathrm{H}_{2} \mathrm{~S}$ under pressure above $90 \mathrm{Gpa}$. Here, we work on three forms of structures for $\mathrm{H}_{3} \mathrm{~S}$ ( cubic, doubled cubic, twin ) to study the impact of high pressure on all of the lattice constants, the total energy, the band structures and the density of states for each form of this compound. We use Castep code to calculate all of the lattice constants, the total energy and to anlys structures and the density of states for each form of $\mathrm{H}_{3} \mathrm{~S}$ under selected values of pressure starte from $0 \mathrm{Gpa}$ to 325 $\mathrm{Gpa}$. We find the relationship between pressure and both the lattice constant \& Total Energy for $\mathrm{H}_{3} \mathrm{~S}$ in different styles (cubic, cubic doubled, twin) structures is an inverse. In addition, the highest pressure superconductivity for cubic $\mathrm{H}_{3} \mathrm{~S}$ is $0 \mathrm{Gpa}$. As for doubled cubic style for $\mathrm{H}_{3} \mathrm{~S}$, the highest pressure superconductivity is $325 \mathrm{Gpa}$, where the highest pressure superconductivity for twin $\mathrm{H}_{3} \mathrm{~S}$ is $325 \mathrm{Gpa}$.
\end{abstract}

\section{General Terms}

Total Energy for $\mathrm{H}_{3} \mathrm{~S}$

\section{Keywords}

Lattice Constant and Total Energy for $\mathrm{H}_{3} \mathrm{~S}$

\section{INTRODUCTION}

The metallicity is a necessary condition for superconductivity where the insulating and semiconducting materials become metallic under high pressure because, with increasing electronic density, the kinetic energy grows faster than the potential energy [1, 2]. Wigner and Huntington in 1935 suggested the possibility of a metallic modification of hydrogen under very high pressures [3]. Ashcroft and Richardson expected [4, 5] hydrogen to become metallic under pressure and also the possibility to be a hightemperature superconductor. The high critical temperature $\boldsymbol{T}_{\boldsymbol{c}}$ of hydrogen $[6,7]$ is a consequence of its low atomic mass leading to high energy vibrational modes and in turn to a large phase space available for electron-phonon scattering to induce superconductivity [8]. Recently, it was reported that sulfur hydride $\mathrm{H}_{2} \mathrm{~S}$, when pressurized, becomes metallic and superconducting. For pressures above $180 \mathrm{GPa}$ an extremely high transition temperature of about $190 \mathrm{~K}$ was measured [9]. This $\boldsymbol{T}_{\boldsymbol{c}}$ is higher than in other superconductors known so far, including Curates and Pnictides. The experimental evidence is supported theoretically, and crystal prediction methods suggest that the system becomes superconducting with a $\boldsymbol{H}_{3} \mathrm{~S}$ stoichiometry $[10,11,12]$. on the other side, Emeritus's experiments on pressurized sulfur hydride appeared that $\mathrm{H}_{3} \mathrm{~S}$ metal has the highest known superconducting critical temperature $\mathrm{Tc}=203 \mathrm{~K}$ [13]. In this work we use CASTEP code to calculate both the lattice constants and the total energy for $\mathrm{H}_{3} \mathrm{~S}$ compound at different values of pressure.

\section{BACKGROUND}

\subsection{Lattice Constant}

The cross section steady, or grid parameter, alludes to the physical measurement of unit cells in a precious stone grid. Cross sections in three measurements, for the most part, have three grid constants, alluded to as a, b, and c. In any case, in the uncommon instance of cubic precious stone structures, the majority of the constants are equivalent, and we just allude to a. Additionally, in hexagonal precious stone structures, the a and $\mathrm{b}$ constants are equivalent, and we just allude to the a and c constants. A gathering of cross section constants could be alluded to as grid parameters. In any case, the full arrangement of cross section parameters comprises of the three grid constants and the three points between them. For instance, the grid steady for precious stone is a $=3.57 \AA$ at $300 \mathrm{~K}$. The structure is equilateral in spite of the fact that its real shape can't be resolved from just the cross section steady. Besides, in genuine applications, commonly the normal grid consistent is given. Close to the gem's surface, cross section steady is influenced by the surface recreation that outcomes in a deviation from its mean esteem. This deviation is particularly vital in nanocrystals since surface-to-nanocrystal center proportion is large.As cross section constants have the measurement of length; their SI unit is the meter. Cross section constants are regularly on the request of a few angstroms (i.e. tenths of a nanometer). Cross section constants can be resolved utilizing methods, for example, X-beam diffraction or with a nuclear constrain magnifying instrument. Cross section consistent of a precious stone can be utilized as a characteristic length standard of nanometer range.

\subsection{Cubic $\mathrm{H}_{3} \mathrm{~S}$ around $190 \mathrm{GPA}$}

The report by Drozdov, Eremets, and Troyan (DET) of superconductivity up to $\mathrm{Tc}=190 \mathrm{~K}$ in $\mathrm{H} 2 \mathrm{~S}$ packed to the 200 Gpa administration has reignited fervor in the likelihood of accomplishing room temperature superconductivity. This report expands on past achievement of weight upgrade of Tc in a assortment of sorts of materials: from $134 \mathrm{~K}$ to $164 \mathrm{~K}$ in the cuprate $\mathrm{Hg} 2223$, from zero to $20-25 \mathrm{~K}$ in the straightforward metals $\mathrm{Li}, \mathrm{Ca}$, and $\mathrm{Y}$, and from zero to $14 \mathrm{~K}$ in the separator silicon. An expected central point is the expansion in the phonon vitality scale with pressure, since it sets the temperature scale for Tc, as pointed out right off the bat 1 and looked into all the more as of late by Ashcroft in anticipating conceivable room temperature superconductivity in metallic hydrogen. The recently reported high estimations of Tc seem to affirm hypothetical expectations that originated before the test. Applying molecule swarm precious stone structure look methods established on thickness utilitarian hypothesis, Li et al. anticipated competitor stable precious stone structures of $\mathrm{H} 2 \mathrm{~S}$ up to $220 \mathrm{Gpa}$. These forecasts were trailed by straight reaction counts of the phonon range $\omega \mathrm{Q}$, electron-phonon network components, and at long last the Eliashberg ghastly 
capacity $\alpha 2 \mathrm{~F}(\omega)$, from which Tc can be computed, depending just gently on the assumed estimation of the hindered Coulomb aversion $\mu *=0.10-0.13$. For weights of $140-180$

Gpa, they got an electron-phonon coupling quality $\lambda=1.0$ 1.2 , an Allen-Dynes trademark recurrence $\omega \log \sim 1000 \mathrm{~K}$, and $\mathrm{Tc}$ of $40 \mathrm{~K}$ at $140 \mathrm{Gpa}$ and cresting at $80 \mathrm{~K}$ at $160 \mathrm{Gpa}$. While $80 \mathrm{~K}$ is well shy of the reported $\mathrm{Tc}=190 \mathrm{~K}$, the outcome is persuading that high $\mathrm{Tc}$ is anticipated in $\mathrm{H} 2 \mathrm{~S}$ at high weight. The sister stoichiometry $\mathrm{H} 3 \mathrm{~S}$ has been investigated in extremely comparative mold by Duan et al. Predicting structures to more than $200 \mathrm{Gpa}$, their direct reaction comes about for $\operatorname{Im}^{-} \mathrm{mH} 3 \mathrm{~S}$ prompted to substantial computed estimations of electronphonon coupling quality $\lambda=2.0-2.2$, recurrence scales $\omega \log \sim 1300 \mathrm{~K}$, and estimations of Tc up to $200 \mathrm{~K}$. In the estimations of $\mathrm{Li}$ et al. Duan et al., the high estimations of $\omega \log$ are normal from the foreseen increment of drive constants as volume is diminished. The substantial estimations of $\lambda$, a component of at least two over generally other good superconductors (counting $\mathrm{MgB} 2$ ), infer that the electronic network components are considerably bigger than in about all known conventional superconductors.

\section{THE ACCESS TO THE SUPERCONDUCTOR OF SULFUR HYDRIDE $\left(\mathrm{H}_{3} S\right)$}

Before 1911, the prevailing belief was that all materials become superconductors for electricity only at a temperature of an absolute zero. In that year (1911), the Dutch physicist Heike Kamerlingh Onnes found that mercury becomes pure resistance equal to zero at a temperature of $-452^{\circ} \mathrm{F}$ or $4 \mathrm{~K}$, and can get these low grades by liquefying helium gas. Also, Onnes discovered that if he applied

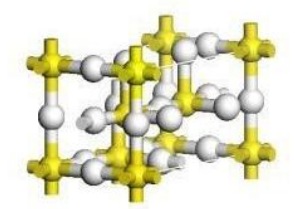

Figure 1-C: the twin structure for $\mathrm{H}_{3} \mathrm{~S}$ at lattice constants $\mathrm{a}=6.04 \mathrm{~b}=\mathrm{c}=3.02 A_{o}$ and angels $\alpha=\beta=\gamma=90$ degrees. $\mathrm{a}$ strong magnetic field on this mercury, the superconductivity vanished as quickly as it had arrived [14]. After all, we can say that superconductors properties are not limited to conduct electricity without any resistance at certain temperatures called transition temperatures. But that these materials at these temperatures become very sensitive to the magnetic field, where they alienated the external magnetic field, in another word, superconductors are diamagnetic [14]. Then, research and scientific experiments began actively to try to understand this phenomenon and how to get another material to be zero resistance at room temperature. Recently, they have discovered a superconductor of $\mathrm{H}_{3} \mathrm{~S}$ with the critical temperature $T_{c}$ above $200 \mathrm{~K}$ by compressing $\mathrm{H}_{2} \mathrm{~S}$ under pressure above $90 \mathrm{Gpa}$. It was suggested that these materials disintegrate under pressure to elemental sulfur and hydride with higher content of hydrogen which is responsible for the high- temperature superconductivity [15]. In this study, we work on a quadrilateral structure (cubic) for $\mathrm{H}_{3} \mathrm{~S}$ as shown in figure 1 (a, b, c).

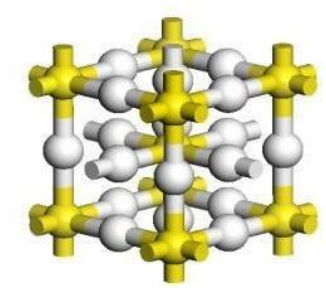

Figure 1-a: the cubic structure for $H_{3} S$ at lattice constants $\mathrm{a}=\mathrm{b}=\mathrm{c}=3.02$ Ao and angels $\alpha=\beta=\gamma=90$ degrees.

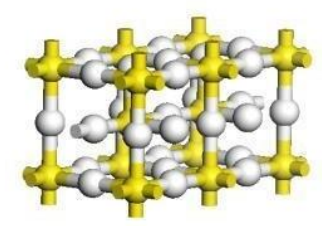

Figure 1-b: the twin structure for $\mathrm{H}_{3} \mathrm{~S}$ at lattice constants $a=6.04$

$\mathrm{b}=\mathrm{c}=3.02$ Ao and angels $\alpha=\beta=\gamma=90$ degrees.

\section{RESULTS AND METHODS}

Table 1-a: Detailed structural information of $H_{3} S$ (cubic) compound at selected pressures

\begin{tabular}{ccc}
\hline $\begin{array}{c}\text { Pressure } \\
\text { (GPA) }\end{array}$ & Lattice constant & Total energy \\
\hline 0 & (A) & (EV) \\
175 & $\mathrm{a}=\mathrm{b}=\mathrm{c}=3.722$ & -644.4 \\
225 & $\mathrm{a}=\mathrm{b}=\mathrm{c}=3.034$ & -606.3 \\
275 & $\mathrm{a}=\mathrm{b}=\mathrm{c}=2.961$ & -597.9 \\
325 & $\mathrm{a}=\mathrm{b}=\mathrm{c}=2.900$ & -590.0 \\
& $\mathrm{a}=\mathrm{b}=\mathrm{c}=2.848$ & -582.6 \\
\hline
\end{tabular}




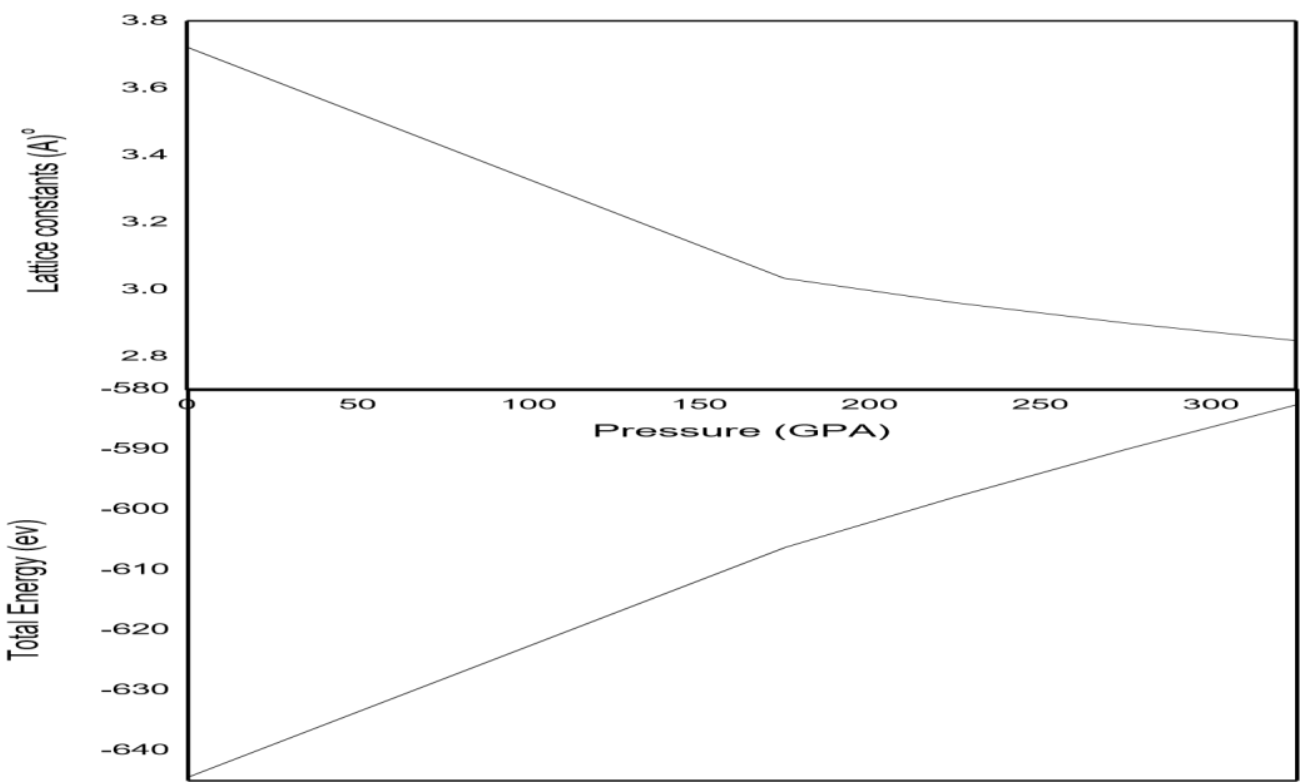

Figure 4-a: The relationship between pressure and both the lattice constant \& Total Energy for $\mathrm{H}_{3} S$ (cubic structure)

Table 1-b: Detailed structural information of $H_{3} S$ (cubic-doubled) compound at selected pressures where $\alpha=\beta=\gamma=90$ degrees

\begin{tabular}{ccc}
\hline $\begin{array}{c}\text { Pressure } \\
(\text { GPA })\end{array}$ & Lattice constant & Total energy \\
& $(\mathrm{A})$ & $(\mathrm{EV})$ \\
\hline 0 & $\mathrm{a}=7.474, \mathrm{~b}=\mathrm{c}=3.692$ & -1289.18 \\
175 & $\mathrm{a}=6.093, \mathrm{~b}=\mathrm{c}=3.027$ & -1212.80 \\
225 & $\mathrm{a}=5.951, \mathrm{~b}=\mathrm{c}=2.954$ & -1196.02 \\
275 & $\mathrm{a}=5.824, \mathrm{~b}=\mathrm{c}=2.895$ & -1180.22 \\
325 & $\mathrm{a}=5.709, \mathrm{~b}=\mathrm{c}=2.844$ & -1165.21 \\
\end{tabular}

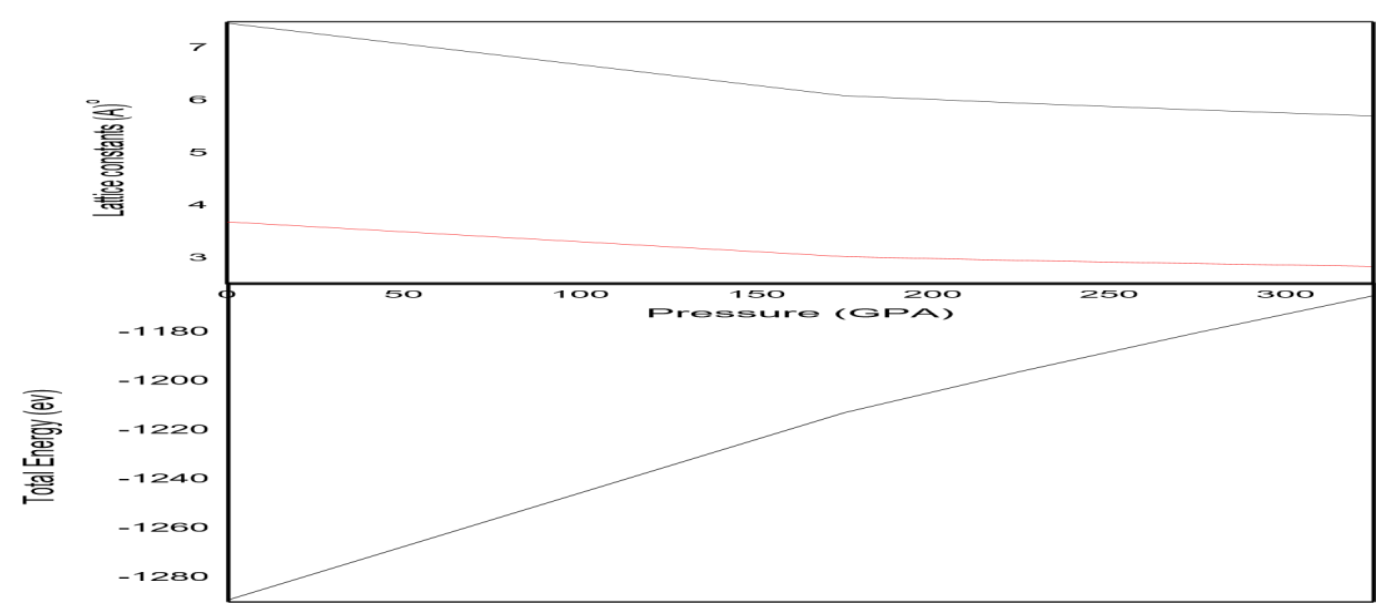

Figure 2-b: The relationship between pressure and both the lattice constant \& Total Energy for $\mathrm{H}_{3} S$ (cubic doubled structure) where the red line indicates the lattice constants b\& $\mathrm{c}$ 
Table 1-c: Detailed structural information of $H_{3} S$ (Twin) compound at selected pressures where $\alpha=\beta=\gamma=90$ degrees.

\begin{tabular}{ccc}
\hline $\begin{array}{c}\text { Pressure } \\
(\mathrm{GPA})\end{array}$ & Lattice constant & Total energy \\
& $(\mathrm{A})$ & $(\mathrm{EV})$ \\
\hline 0 & $\mathrm{a}=7.481, \mathrm{~b}=\mathrm{c}=3.696$ & -1289.17 \\
175 & $\mathrm{a}=6.094, \mathrm{~b}=\mathrm{c}=3.030$ & -1212.69 \\
225 & $\mathrm{a}=5.954, \mathrm{~b}=\mathrm{c}=2.956$ & -1196.00 \\
275 & $\mathrm{a}=5.826, \mathrm{~b}=\mathrm{c}=2.896$ & -1180.20 \\
325 & $\mathrm{a}=5.712, \mathrm{~b}=\mathrm{c}=2.845$ & -1165.19
\end{tabular}

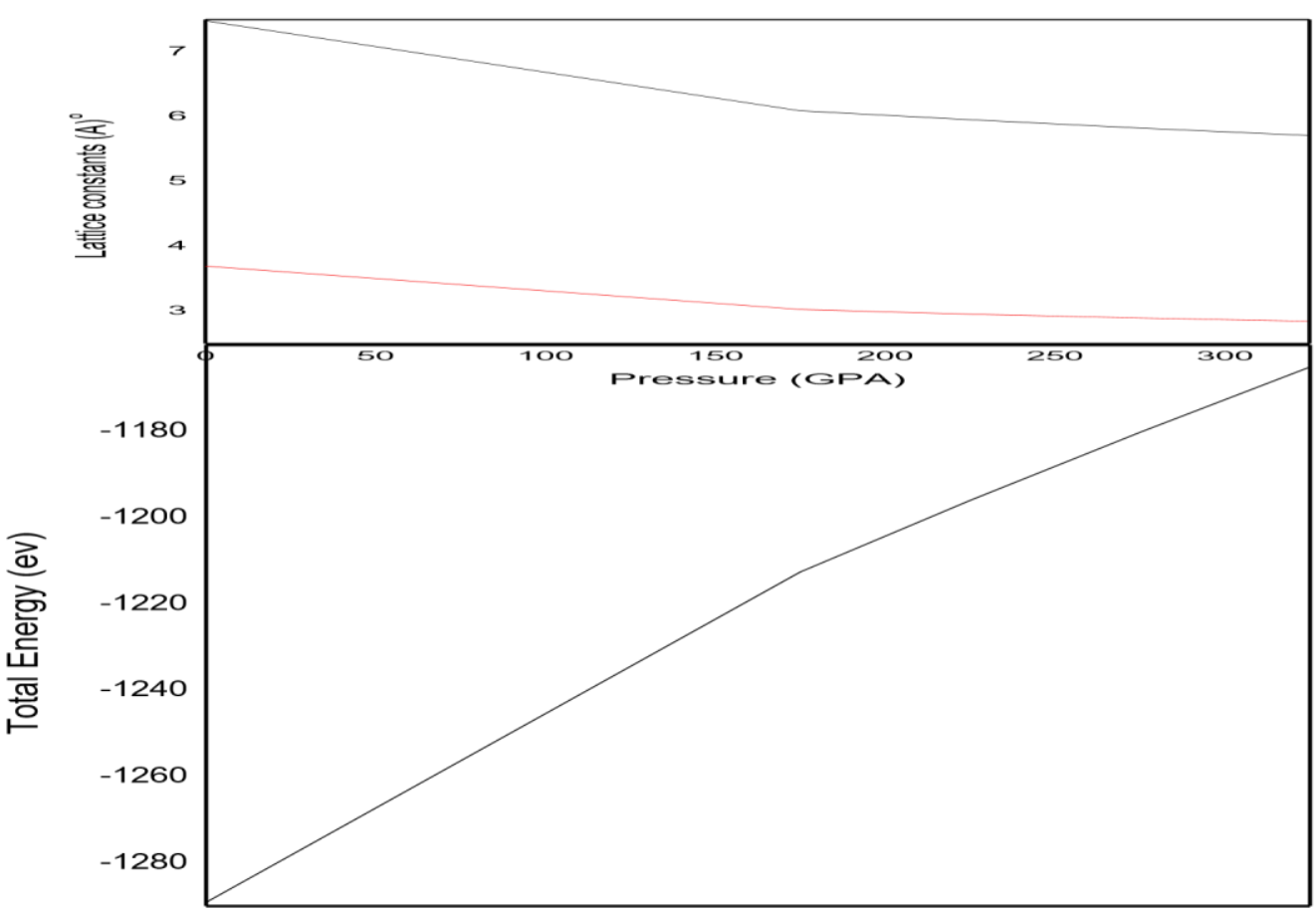

Figure 2-c: The relationship between pressure and both the lattice constant \& Total Energy for $\mathrm{H}_{3} S$ (twin structure) where the red line indicates the lattice constants $b \& c$

Figure 2(a, b, c respectively): The relationship between pressure and both the lattice constant \& Total Energy for $\mathrm{H}_{3} \mathrm{~S}$ in different styles a (cubic), b (cubic doubled), c (twin) structures. It is clear that an inverse relationship here between these variables, where with increasing pressures, the lattice constants, and total energy values are decreasing, or in other words, the total energy becomes more negative. In figure (2a), the lattice constants decline from $3.72 \mathrm{~A}^{\circ}$ at $0 \mathrm{GPA}$ to 2.84 $\mathrm{A}^{\circ}$ at $325 \mathrm{GPA}$. Also, the total energy value decreases from $644.4 \mathrm{ev}$ to $-582.6 \mathrm{ev}$ at that values of pressure. The same thing happens in figure (2-b), the lattice constants decline from $a=7.47 \& b=c=3.69 \mathrm{~A}^{\circ}$ at 0 GPA to $a=5.70 \& b=c=2.84$ $\mathrm{A}^{\circ}$ at $325 \mathrm{GPA}$, also the total energy value decreases from $1289.1 \mathrm{ev}$ to $-1165.2 \mathrm{ev}$ at that values of pressure. As for figure (2-c), the lattice constants decline from $a=6.09 \&$ $\mathrm{b}=\mathrm{c}=3.03 \mathrm{~A}^{\circ}$ at $0 \mathrm{GPA}$ to $\mathrm{a}=5.71 \& \mathrm{~b}=\mathrm{c}=2.84 \mathrm{~A}^{\circ}$ at $325 \mathrm{GPA}$, also the total energy value decreases from $-1289.1 \mathrm{ev}$ to $1165.1 \mathrm{ev}$ at that values of pressure.

\section{THE BAND STRUCTURES AND THE DENSITY OF STATES FOR $\mathrm{H}_{3} \mathrm{~S}$ AT VARIOUS VALUES OF PRESSURE}

In general, the band structure describes the changes of the energies of all of the states with $\mathrm{k}$. Because $\mathrm{k}$ is a $3 \mathrm{D}$ vector, it plots the energies along specific high symmetry directions. The powers along these lines represent either maximum or minimum energy for the bands across the whole Brillouin zone [14]. Here, we use CASTEP code to plot the band structures for $\mathrm{H}_{3} \mathrm{~S}$ in various forms (cubic, doubled cubic and twin) under high pressures ranging from 0 GPA up to 225 GPA. [See figure3(a,b,c,d,e), figure $4(\mathrm{a}, \mathrm{b}, \mathrm{c}, \mathrm{d}, \mathrm{e})$ and figure $5(\mathrm{a}, \mathrm{b}, \mathrm{c}, \mathrm{d}, \mathrm{e})]$ 

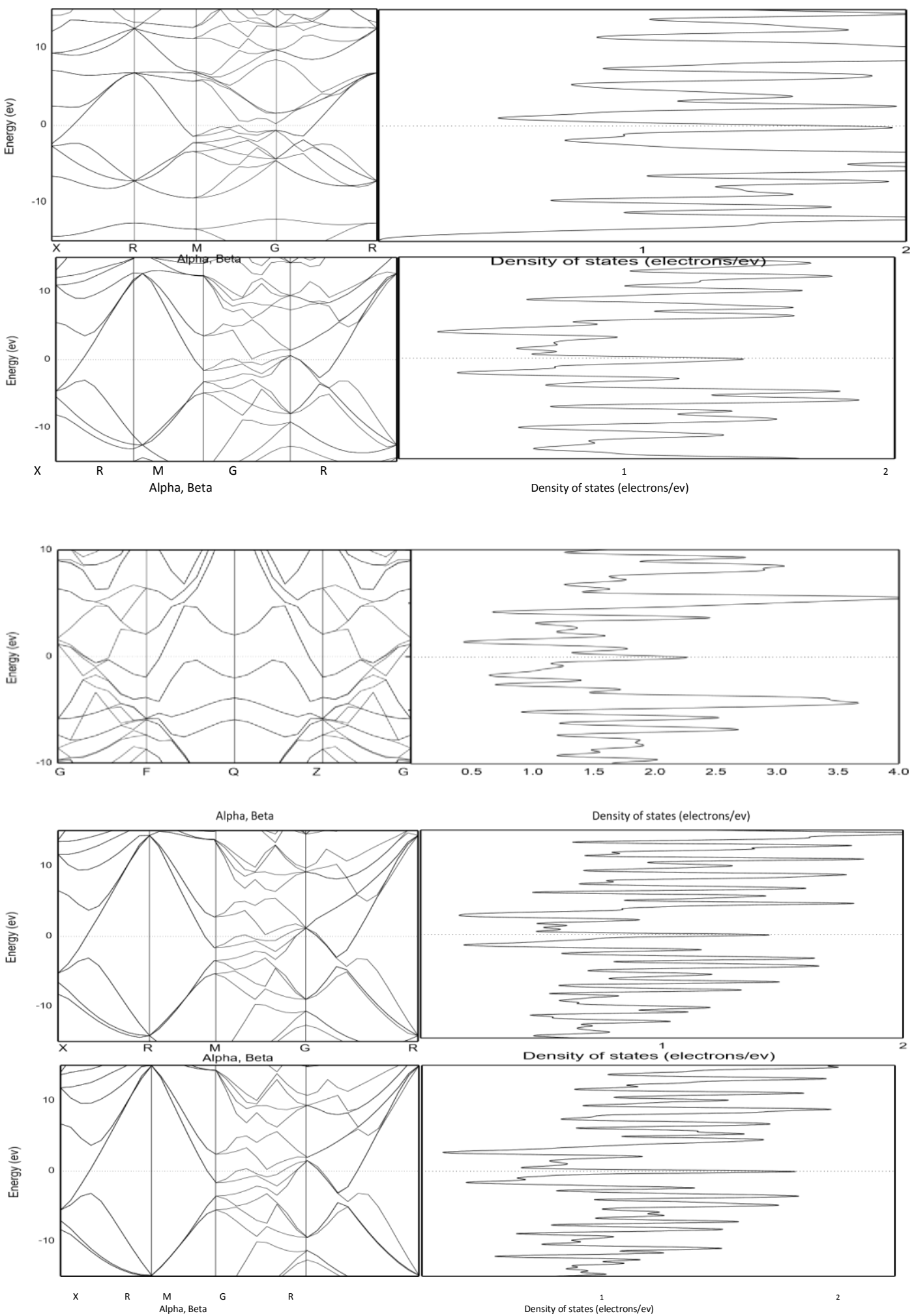

Figure 3 (a, b, c, d and e respectively): The band structure \& DOS for $\mathrm{H}_{3} \mathrm{~S}$ in cubic style at $\mathrm{P}=0$ GPA, P $=175$ GPA,P $=225$ GPA, P $=275 \mathrm{GPA}$ and $\mathrm{P}=325 \mathrm{GPA}$ respectively. In figure a, the density of states at $0 \mathrm{GPA}$ is equal to1.92 electrons/ev and this is the greatest value here. For both figures $\mathrm{b}$ and $\mathrm{c}$, the densities of states are almost same where at 175 GPA it is equal to 1.40 electrons/ev and it is 1.41 electrons/ev at 225 GPA. In next figure (d), the density of states at 275 GPA is equal to1.45 electrons/ev. At the last figure (e), the density of states at $325 \mathrm{GPA}$ is equal to1.6 electrons/ev. 

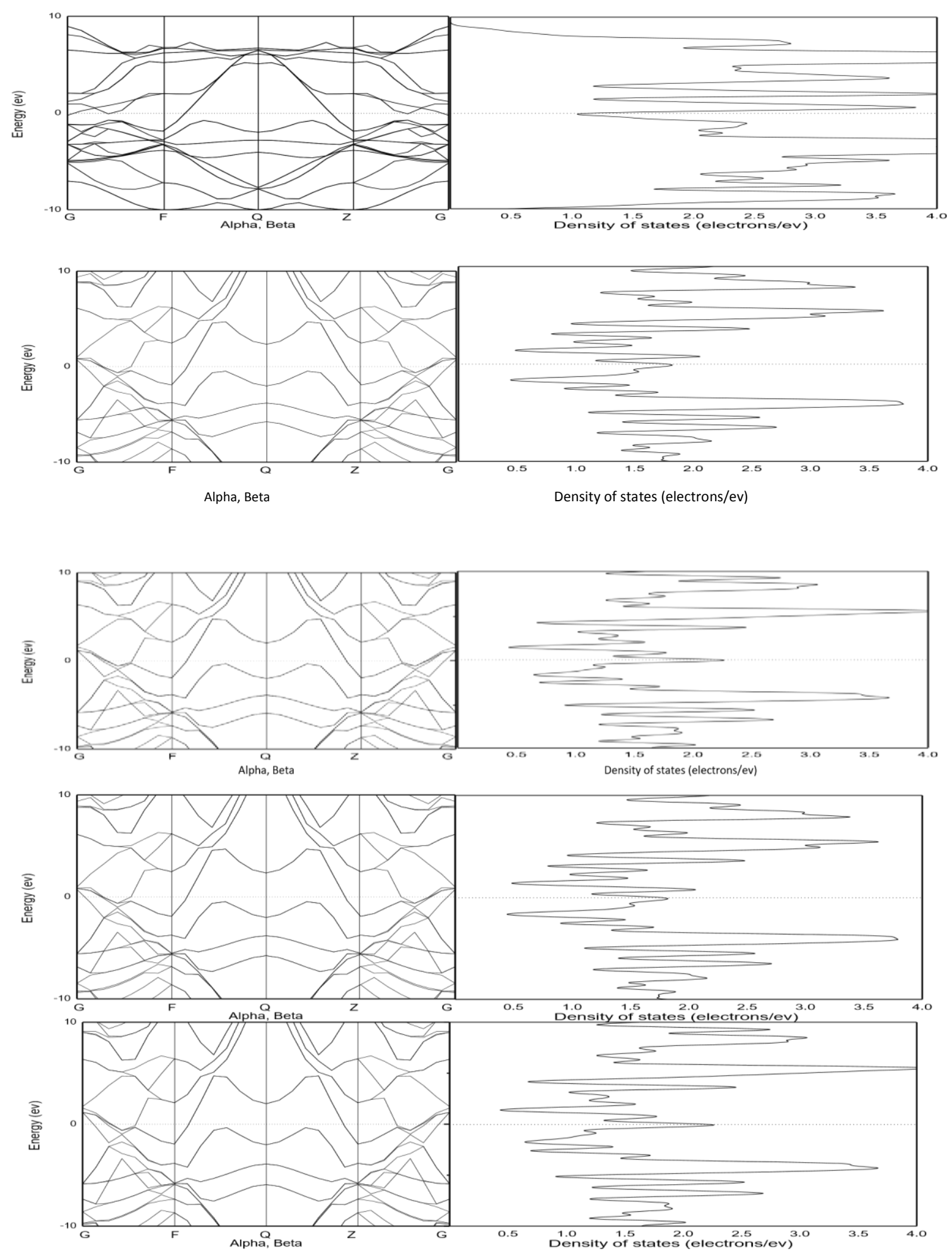

Figure 4 (a, b, c, d and e respectively): The band structure \& DOS for $\mathrm{H}_{3} \mathrm{~S}$ in doubled cubic style at $\mathrm{P}=0$ GPA,P $=175 \mathrm{GPA}, \mathrm{P}=225$ GPA, P $=275 \mathrm{GPA}$ and $\mathrm{P}=325 \mathrm{GPA}$ respectively. In figure a, the density of states at $0 \mathrm{GPA}$ is equal to1.1 electrons/ev and this is the lowest value here. In figures b, the density of states is 1.2 electrons/ev at 175 GPA. In both figures $\mathrm{c}$ and d, the densities of states are almost same where at $225 \mathrm{GPA}$ it is equal to 1.75 electrons/ev and it is 1.76 electrons/ev at $275 \mathrm{GPA}$. In the last figure(e), the density of states at $325 \mathrm{GPA}$ is equal to2.25 electrons/ev and this is the greatest value of density of states here. 

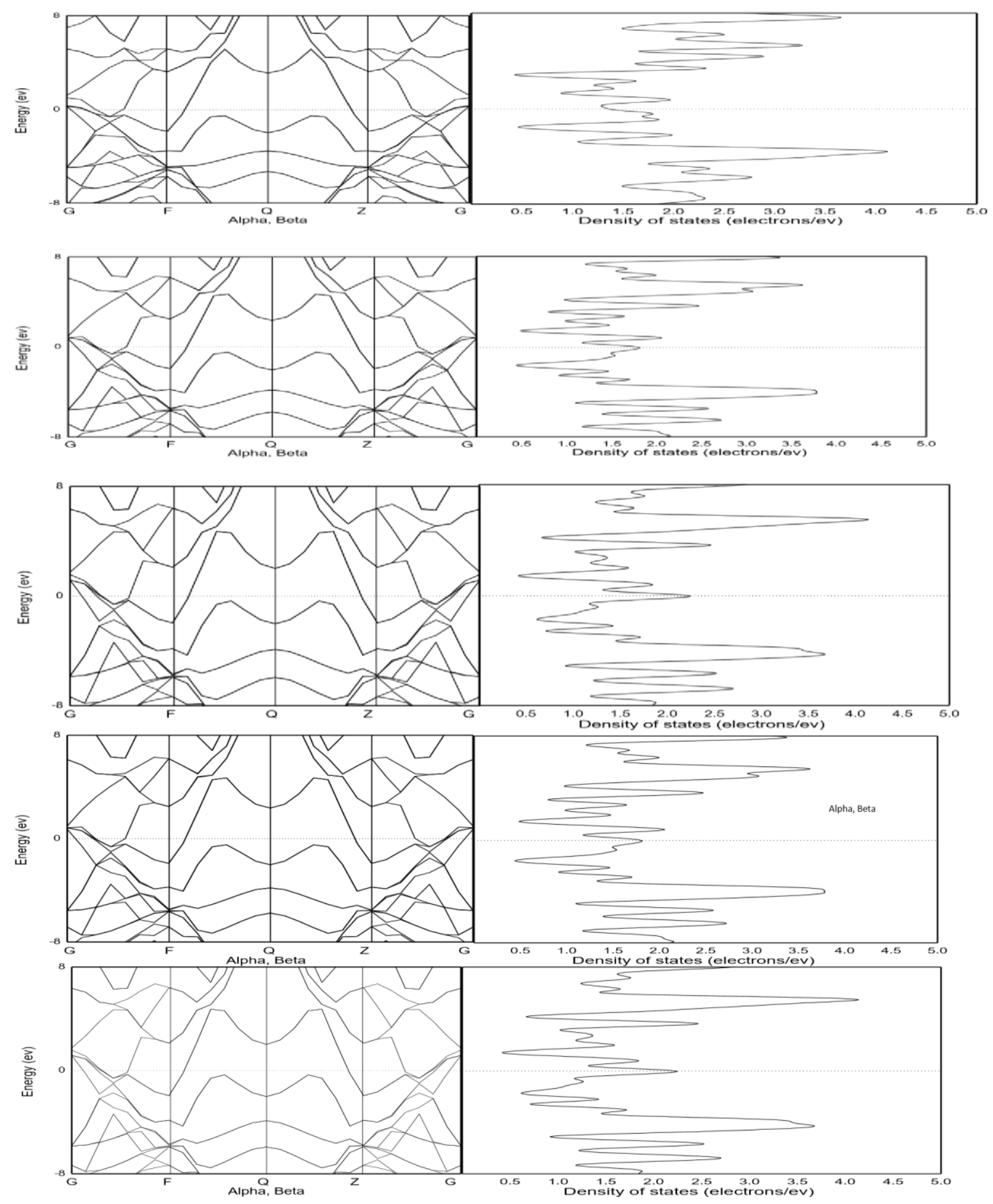

Figure 5 (a, b, c, d and e respectively): The band structure \& DOS for $\mathrm{H}_{3} \mathrm{~S}$ in doubled cubic style at $\mathrm{P}=0$ GPA, $\mathrm{P}=175$ GPA, $\mathrm{P}=225$ GPA, P $=275 \mathrm{GPA}$ and P $=325 \mathrm{GPA}$ respectively. In figure a, the density of states at $0 \mathrm{GPA}$ is equal to1.1 electrons/ev and this is the lowest value here. In figures b, the density of states is 1.2 electrons/ev at 175 GPA. In both figures c and d, the densities of states are almost same where at $225 \mathrm{GPA}$ it is equal to 1.75 electrons/ev and it is 1.76 electrons/ev at $275 \mathrm{GPA}$. In the last figure (e), the density of states at $325 \mathrm{GPA}$ is equal to2.25 electrons $/ \mathrm{ev}$ and this is the greatest value of density of states here. We can say that the results for the last two figures (4 and 5) completely equal. 


\section{CONCLUSION}

In this work by results, we find the relationship between pressure and both the lattice constant \& Total Energy for $\mathrm{H}_{3} \mathrm{~S}$ in different styles (cubic, cubic doubled, twin) structures. It is clear that an inverse relationship here between these variables, where with increasing pressures, the lattice constants, and total energy values are decreasing. Also, the highest pressure superconductivity for cubic $\mathrm{H}_{3} \mathrm{~S}$ is 0 GPA where the densityof states at is equal to1.92 electrons/ev. As for doubled cubic style for $\mathrm{H}_{3} \mathrm{~S}$, the highest pressure superconductivity is 325 GPA where the density of states is equal to2.25 electrons/ev. Finally, the highest pressure superconductivity for twin $\mathrm{H}_{3} \mathrm{~S}$ is 325 GPA where the density of states is equal to 2.25 electrons $/ e v$ and these values are completely same to what we have in the doubled cubic style of $H_{3} S$.

\section{ACKNOWLEDGMENTS}

The author would like to thank Dr. Larry Wang for his comments and suggestions during the prepration of the maniscript. Research is supprted by SACM.

\section{REFERENCES}

[1] K. Shimizu, K. Amaya, and N. Suzuki, Journal of the Physical Society of Japan 74, 1345 (2005), http://dx.doi.org/10.1143/JPSJ.74.1345.

[2] C. Buzea and K. Robbie, Superconductor Science and Technology 18, R1 (2005).

[3] E. Wigner and H. B. Huntington, The Journal of Chemical Physics 3, 764 (1935).

[4] N. Ashcroft, Phys. Rev. Lett. 21, 1748 (1968).

[5] C. F. Richardson and N. W. Ashcroft, Phys. Rev. Lett.78, 118 (1997).
[6] P. Cudazzo, G. Profeta, A. Sanna, A. Floris, A.

Continenza, S. Massidda, and E. Gross, Phys. Rev. Lett. 100, 257001 (2008).

[7] P. Cudazzo, G. Profeta, A. Sanna, A. Floris, A. Continenza,S. Massidda, and E. K. U. Gross, Phys. Rev. B 81, 134505 (2010).

[8] J. Bardeen, L. N. Cooper, and J. R. Schrieffer, Phys.Rev. 108, 1175 (1957).

[9] A. Drozdov, M. I. Eremets, and I. A. Troyan, arXiv:1412.0460 [cond-mat.supr-con] (2014).

[10] Y. Li, J. Hao, H. Liu, Y. Li, and Y. Ma, The Journal of Chemical Physics 140, (2014).

[11] D. Duan, Y. Liu, F. Tian, D. Li, X. Huang, Z. Zhao,H.Yu,B. Liu, W. Tian, and T. Cui, Sci. Rep. 4 (2005), http://dx.doi.org/10.1038/srep06968.

[12] N. Bernstein, C. S. Hellberg, M. D. Johannes, I. I. Mazin,and M. J. Mehl, ArXiv e-prints (2015), arXiv:1501.00196 [cond-mat.supr-con].

[13] A Bianconi, T Jarlborg - Novel Superconducting Materials, $2015 \quad-\quad$ degruyter.com https://www.degruyter.com/downloadpdf/j/nsm.2013.1.is sue1/ nsm-2015-0006/nsm-2015-0006.xml

[14] http://www.explainthatstuff.com/superconductors.html

[15] Crystal Structure of 200 K-Superconducting Phase of Sulfur Hydride $\quad$ System https://arxiv.org/pdf/1509.03156v1.pdf

[16] P.J. Hasnip. DFT Spectroscopy Workshop 2009 http://www.tcm.phy.cam.ac.uk/castep/oxford/hasnip2.pdf 